\title{
Structure of the Performance Management at the Regional Level
}

\author{
M.V. Simonova ${ }^{1}{ }^{*}, N . N$. Gunko $^{1}$, S.A. Kolesnikov ${ }^{2}$, and A.N. Parshin ${ }^{2}$, \\ *Corresponding author: m.simonova@mail.ru. \\ ${ }^{1}$ Samara State University of Economics, Samara, Russia \\ ${ }^{2}$ Samara State Technical University, Samara, Russia
}

\begin{abstract}
In the article authors studied a problem of a practical use of scientific research on performance management on the regional level, suggested a mechanism of an institutional approach to solve the problem through the creation of a vertically integrated system with government and professional organizations in the region, which allows organizing cooperation on different management and economic levels. To justify the creation of the system, analysis of labor productivity growth in the regions of the Russian Federation had been carried out. In the system of productive factors social and economic drivers had been allocated, which can lead to dramatic improvements in productivity in the short term, without any use of considerable investment. Their implementation, however, requires well-developed institutional support. Functional and substantial structure of the regional center for competency of productivity had been developed. It is made for the scientific, methodological and organizational support of the project to improve productivity at the regional's workplaces. The need of creation of harmonized methodology to increase productivity, qualification and methodological process support on the principles of project management had been demonstrated.
\end{abstract}

Keywords: labor productivity, performance management, social and economic factors of productivity improvement, production efficiency.

\section{Introduction}

Implementation of National projects in Russia sets high measurements of economic growth, not less than 5\% of gross domestic product annually, which depends to a large extent on the labor productivity growth rates. The possibility of productivity growth defines by regional specificities of productive infrastructure [1], which differs with industry variety, level of labor potential, development opportunities of transport communications and many others aspects of economic and social life of provinces that need creation of regionals management models. At the same time, country has huge reserves to increase productivity, based on available resources and comparing them with other counties. Reserves to increase productivity consists both through developments of advanced technologies [2] and through wellknown technological solutions, without significant investment in fixed capital, but under the organization of effective cooperation of different governmental and managerial structures, which require scientific and methodological support.

\section{Problem Statement}

Potential, however, that available in each region, underutilized. In the last years there is a decline in development rates in many areas of the economy, including labor productivity growth, which averages no more than $1,3 \%$ a year. With that rate of growth, it is unable to set the economies of regions on the necessary level and represents as an extremely low figure (Fig. 1). 


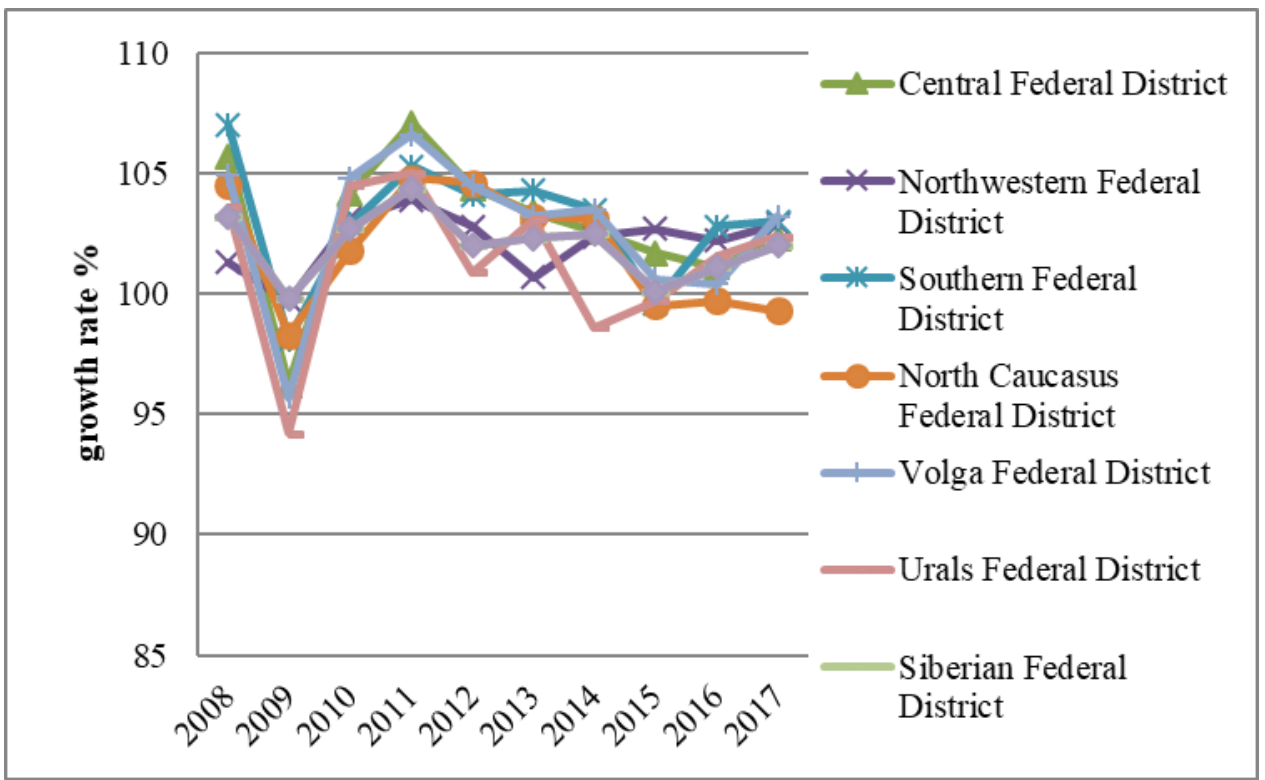

Fig. 1. Dynamics of labor productivity indices in the regions of the Russian Federation. Source: Authors, based on the data of Rosstat [3].

Analysis of labor productivity trends in Federal areas of Russia shows both some differences and some general trends to a minor increase, rate of which cannot provide necessary growth of economic indicators.

\section{Research Questions}

The objective of significant labor productivity growth in the country has number of restrictions including financial nature. Methods and tools to increase productivity are sufficiently well studied by Soviet's scientists of Labor Economics School [4]. They would include technological upgrading of manufacture [5], when due to mechanization and automatization, number of personnel decrease, but the reduction of time to produce products happens, improvement in the quality and enhancing the competitiveness of products [6]. At the same time, in most cases, there are capital and other restrictions for quick investment under the existing need in improving productivity of production [7]. The lack of financial resources holds upgrading of basic means of production, which is the main engine of labor productivity growth [8]. However, labor productivity growth can be achieved not just because of technological innovation, but because of others, low-costed, but nonetheless important methods, which can give significant impact on existing equipment. Low productivity at many Russian enterprises is not only because of the high level of obsolescence of equipment, but also because of high level of different losses, for example number of defects, downtime of equipment, low quality of products, inefficient labor management, low motivation of personnel, and other factors that collectively frame the organizational culture. Without activation of these factors, productivity can be even lower on new equipment rather than on old one [9]. In so doing, awareness among enterprises of the potential improvement in productivity, not by investment methods in the short term, remains extremely weak. There is also a weak chance to make reform by themselves because of staff's workload by current responsibilities and lack of professionals with needed qualification.

\section{Purpose of the Study}

The relevance of the research topic is determined by the fact that among methods to increase productivity, there are very little number of non-investment matters to improve productivity, which can lead to an economic effect. To a large extent, the above social and economic factors [10] depend on combination of managerial tools and methods, applied at the enterprise, but at the same time most of them may be harmonized with certain scientific basis, that can serve as a basis to apply in any enterprise. The application of a harmonized methodology does not require significant investment, however, a need for an organizational and management reforms, painful for each enterprise. The efficiency of such activities can be significantly enhanced by skilled methodological support from specialized regional structures.

\section{Research Methods}

In the production process it is necessary to adherence to the technological parameters of their production, which allow to apply low-investment methods to increase productivity. They are determined by next factors - work organization, production loss, capital productivity and motivation of staff [11]. In order to achieve these goals its 
needed to: set short-, middle- and long-term priorities and goals to increase productivity; optimization of organizational structure through the reduction of duplicated and irrelevant functions; reconciliation and redistribution of responsibilities; outsourcing of functions and others; modification in staff motivation system, which aimed to achieve set goals on increasing productivity; reduction in non-productive losses of working time; establishment of workload standards and other methods [12]. Such instruments also include some action in social, economic and organizational factors of productivity. First group of factors designed to effectively manage human resources of an enterprise, second group - for improving the organization of work. To improve the productivity by traditional methods, managerial and motivational actions are needed, which enable to structure and synchronize operations of numerous participations by methods of project management.

The operational level to increase productivity is an area with the most quantifiable indicators and possibilities to achieve measurable results. Such results are combination of several parameters: value added and earnings by one worker, rate of use of the basic means of production.

\section{Findings}

The Federal Priority Program entitled "Productivity gains and employment reduction" [13], which is currently in force, does not fully reveal effectiveness of laid down activities in terms of focused priorities. One of the problems, that holding back implementation of the Program, is lack of the necessary skills of personnel of enterprises, which improve productivity by systematic and organizational support from government organizations and consulting centers. However, their actions are usually not harmonized and in the conflict between one another. Improving productivity in a short term by traditional technologies, despite significantly lower capital intensity in comparison with creation of new products and methods, still require some inputs: organizational and managerial. To do so in each region there is a need in The Project Offices' creation that manage improving of productivity [14] or The Competence Center, which allows to combine theoretical and methodological development with the requirements of each enterprise. The most appropriate way is to allocate specific structural divisions that will manage increasing productivity in created Research-Educational Centers (REC) (Fig.2).

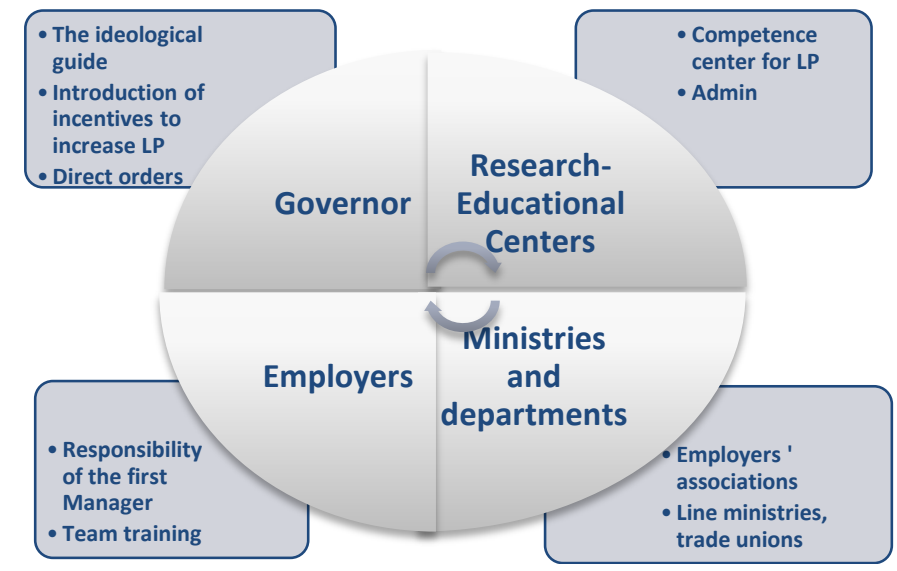

Fig. 2. Interrelations of the regional competence center on labor productivity (LP). Source: Authors.

Submission to the Governor is needed to confirm the considerable value of targets to increase productivity for the region, coordination of goals and tasks to gain better productivity with regards to regional development strategy. The direct supervision of The Competence Center must be guided by REC, but only in the areas of administrative functions, which defined by regulations and REC Council. The actual need of administrative management is determinate by institutional functions, which REC should be vested with. For example, development and functioning of the productivity service market, creation of infrastructural facilities, supporting of legislative initiatives, etc. The proposed structure and course of The Competence Center actions may look as follows (Fig.3). 


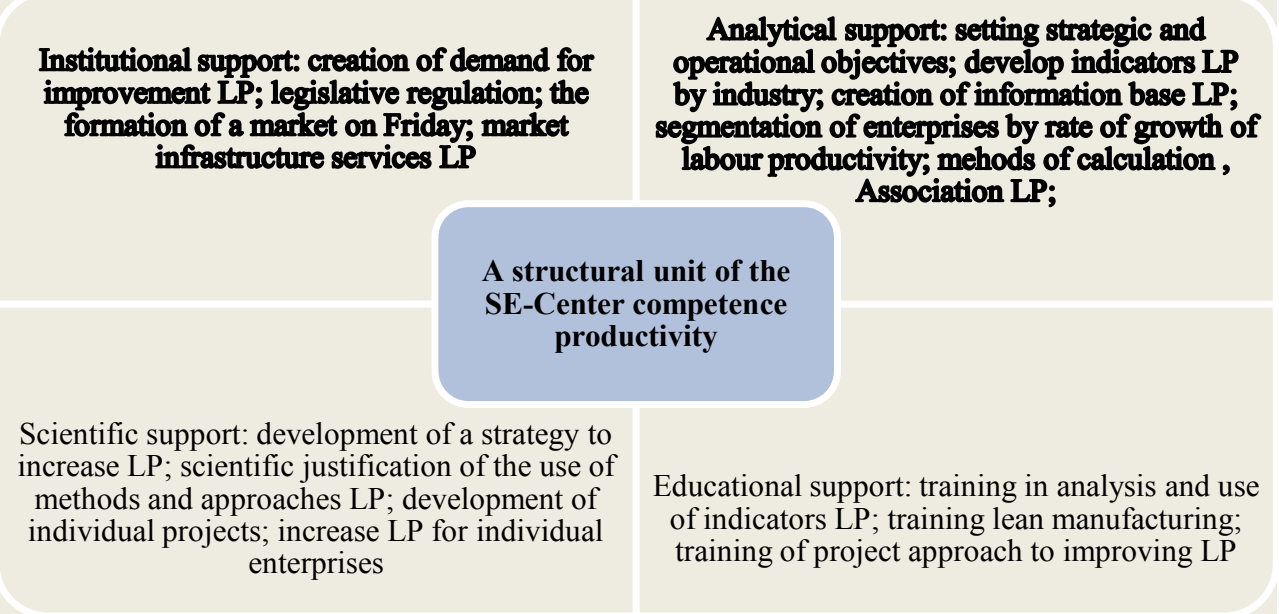

Fig. 3. The proposed functional structure of the competence center of labor productivity (LP). Source: Authors.

Development of methodologies to increase productivity is one of the central issues, because using exactly proven methodologies can show algorithm of well-understood actions with predictable results, which are aimed at the achievement of short-, medium- and long-term goals. When planning efficiency of the system as a whole, its needed to use project approach, which allows to arrange priorities for time and accountability. Such attitude becomes applicable in various systems, including performance management.

\section{Conclusion}

Improvement of productivity requires a systemic, long-term effort on all economic and managerial levels. Studies confirm that it is possible to coordinate various organizational and economic institutions to achieve a common goal: increasing of productivity. Addressing those issues in a short term have been identified social and economic factors, which help to increase productivity through low-cost measures. However, it requires methodological and organizational support, which should be launched at institutional level in each region. In studies was created regional system between governmental and managerial structures, and functional system - The Competence Center - to improve productivity, which allows to organize the process of productivity increasing on principles of project management. In the future, for further research, it entails the development of project model to increase productivity and management tool, both on a regional level and level of an enterprise.

\section{References}

1. A.M. Jarkas, C.G. Bitar, Factors affecting construction labor productivity in Kuwait. Journal of Construction Engineering and Management, 138(7), 811-820 (2014). DOI: 10.1061/(ASCE)CO.1943-7862.0000501.

2. G. Crespi, P. Zuniga, Innovation and productivity: Evidence from six Latin American countries. World Development, 40(2), 273-290 (2012). DOI: 10.1016/j.worlddev.2011.07.010.

3. Federal service of state statistics, Region of Russia, Socio-economic indicators. Stat. proceedings of the Rosstat, Moscow (2018). URL: http://www.gks.ru/free_doc/doc_2018/region/reg-pok18.pdf. Accessed: 05.09.2019.

4. T.O. Selezneva, Economic essence and value of labor productivity. Scientific Discussion: Economics and Management, 5, 91-101 (2015). [in Rus.].

5. C. Syverson, What determines productivity? Journal of Economic Literature, 49(2), 326-365 (2011). DOI: 10.1257/jel.49.2.326.

6. N.N. Shash, A.I. Borodin, Indicators and methods of measuring labor productivity and the possibility of their application in enterprises. Scientific Notes of Petrozavodsk State University, 3-1(148), 96-101 (2015). [in Rus.].

7. E.G. Repina, M.V. Simonova, E.I. Sukhanova, The development of a forecast model of labor productivity management at industrial enterprises. In Y. Silin, Y. Animitsa, E. Dvoryadkina, V. Blaginin (Eds.), Proceedings of the 2nd International Scientific Conference on New Industrialization: Global, National, Regional Dimension (SICNI 2018). Advances in Social Science, Education and Humanities Research, 240 (pp. 96-99). Atlantis Press: Paris (2018). DOI: 10.2991/sicni-18.2019.20.

8. V.A. Vaisburd, M.V. Simonova, I.V. Bogatyreva, E.G. Vanina, E.P. Zheleznikova, Productivity of labor and salaries in Russia: Problems and solutions. International Journal of Economics and Financial Issues, 6(5S), 157-165 (2016). 
9. V.A. Lobanova, N.V. Trofimova, Factor analysis of social labor productivity in the Volga federal district. Bulletin of Belgorod State Technological University named after V.G. Shukhov, 5, 251-255 (2015). [in Rus.].

10. T.I. Ovchinnikova, Y.A. Salikov, A.V. Markov, Productivity and technological development aggregate factors of competitiveness of regional enterprises. Bulletin of Voronezh State University of Engineering Technologies, 1(63), 236-243 (2015). [in Rus.].

11. S.E. Black, L.M. Lync. How to compete: The impact of workplace practices and information technology on productivity. Review of Economics and Statistics, 83(3), 434-445 (2001).

12. A.A. Fedchenko, Methodological approaches to the study of labor productivity. Russian Journal of Labor Economics, 3(1), 41-62 (2016). DOI: 10.18334/et.3.1.35153. [in Rus.].

13. Official website of the Government of the Russian Federation, Passport priority program "increase productivity and employment support» (2017). URL: http://government.ru/news/29354/. Accessed: 01.09.2019.

14. F. Nasirzadeh, P. Nojedehi, Dynamic modeling of labor productivity in construction projects. International Journal of Project Management, 31(6), 903-911 (2013). DOI: 10.1016/j.ijproman.2012.11.003. 